\title{
Pernicious anaemia in the textile industry
}

\author{
Eve Roman, Valerie Beral, Silvia Sanjose, Richard Schilling, Ann Watson
}

\begin{abstract}
The objective was to examine whether the observed excess mortality from anaemia in textile and clothing workers was associated with any specific anaemia type or occupational activity. The design was a death certificate based case-control study of textile and clothing workers who died in England and Wales in the years surrounding the decennial censuses of 1961, 1971, and 1981. The main outcome measures were type of anaemia, place of residence, place of birth, and occupation. The frequency of the different types of anaemia in textile and clothing workers differed from that of England and Wales with relatively more deaths from pernicious anaemia than in the country as a whole ( 74 observed $v 55$ expected deaths). Within the industry, those whose death was attributed to pernicious anaemia were more than twice as likely as other textile and clothing workers to have worked in textile mills (odds ratio $=2.4,95 \%$ confidence interval $1 \cdot 4-4 \cdot 2)$. These results could not be explained by age, sex, place of residence, or place of birth, and review of the death certificates did not suggest that pernicious anaemia as a cause of death had been recorded in error. Historical support for the finding was found in the Registrar General's 1931 decennial supplement on occupational mortality, in which the standardised mortality ratio from pernicious anaemia in male textile mill workers was estimated to be twice that of the general population. In conclusion, occupational factors, specifically work in textile mills,
\end{abstract}

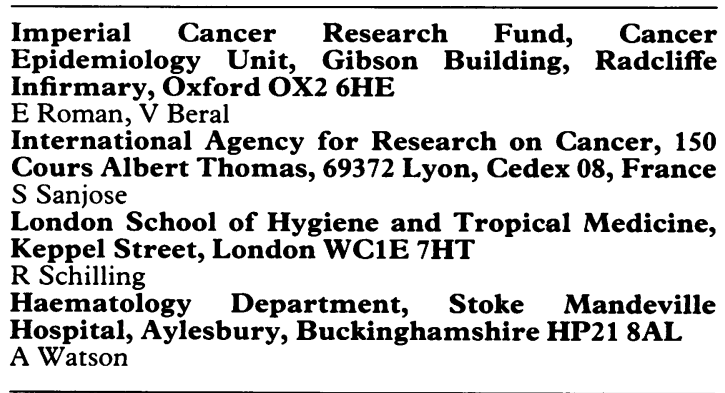

could be implicated in the pathogenesis of pernicious anaemia. The aetiology of this disease is not well understood and further study of pernicious anaemia in textile mill workers is required.

Mortality from anaemia and related disorders of the haematopoietic system have consistently been found to be increased in textile and clothing workers, although there is little information about the types of anaemia and the occupations concerned. ${ }^{1-5}$

We describe an analysis of the occupations and causes of death in textile and clothing workers who died in England and Wales in the years surrounding the decennial censuses of 1961, 1971, and 1981. The aim was to assess whether any specific anaemia types were associated with any particular occupational activities within the textile and clothing industries.

\section{Data and methods}

The study was of a case-control design. Cases and controls were men and women aged between 15 and 74 and classified by the Office of Population Censuses and Surveys (OPCS) as textile and clothing workers. Cases were those who died with anaemia coded as the underlying cause of death ${ }^{6}$ and controls were randomly selected textile and clothing workers with conditions other than anaemia coded as the underlying cause of death. Controls were matched to cases by sex, exact age, and exact year of death. Information on occupation was available for those whose death was attributed to anaemia for the five years 1959-63 around the 1961 census; for the five years $1970-73$ and 1975 around the 1971 census (data for 1974 were not computerised); and for the four years $1979-80$ and $1982-83$ around the 1981 census (data for 1981 were not available because of industrial action by registrars). Four controls for each case were selected for the years around the 1981 census, and three for each case for the years around the 1961 and 1971 censuses. Information about potential controls was not available on computer for 1973 and 1975, and cases who died in these two years were matched to controls who died in 1972 .

Copies of 227 cases and 716 control death certificates were provided by the OPCS. On review, 38 $(5 \%)$ of controls were excluded, either because 
anaemia was mentioned as an associated cause of death $(2 \%)$ or because the stated occupation was not textile or clothing (3\%). No cases were excluded. All death certificates contained information on sex, date of birth, date of death, place of death, cause(s) of death, and occupation. Place of birth was recorded for deaths occurring in 1970 or later.

Subjects were assigned to one of three main occupational groups: textile mill work, other textile manufacturing work, or textile goods production and clothing. Whether the industry was cotton, wool, or silk was stated on the death certificates of $311(76 \%)$ of the 408 textile mill workers. Wool and cotton production tend to be located in specific areas of north west England so where industry was not recorded, a listing giving place of death, year of death, and occupation was reviewed and a presumptive industry code, either wool or cotton, was assigned by RS. This was done without knowledge of case or control state.

The underlying cause of death of cases was coded according to the revision of the International Classification of Diseases effective at the time of death. ${ }^{6}$ Place of death was coded to county as defined in the 1974 reorganisation of England and Wales ${ }^{7}$ and place of birth was coded to county of birth if in the United Kingdom, or to country of birth if abroad.

The data were entered onto microcomputer using the data base management system Dbase III ${ }^{8}$ The data on anaemia in textile and clothing workers were examined in two ways. Firstly, the distribution of deaths attributed to different types of anaemia was compared with the distribution expected on the basis of the experience of England and Wales as a whole. The age, sex, and calendar year specific proportions of all anaemia deaths attributed to the specific anaemias of interest in England and Wales were applied to the total age, sex, and year specific anaemia deaths in textile and clothing workers. ${ }^{910}$ Secondly, the occupational distribution of textile and clothing workers whose deaths were attributed to anaemia was compared with that of their matched controls whose deaths were attributed to other causes using the matched case-control option of the statistical analysis package EGRET. ${ }^{\text {" }}$ The risk in each occupational group was compared with the risk in the remaining occupations.

\section{Results}

Table 1 gives information on the sex, age, and region of residence at the time of death of the 227 textile and clothing workers who died from anaemia in the years under study. More deaths were attributed to anaemia in women than in men, the per cent of women increasing over time from $53 \%$ in $1959-63$ to $71 \%$ in 1979-83. Around $75 \%$ of deaths occurred in those aged 65 or older, and nearly $60 \%$ were in residents of the textile manufacturing areas of north west England in the bordering counties of greater Manchester, west Yorkshire, and Lancashire. Where place of birth was recorded, $95 \%$ of deaths were to persons born in the United Kingdom.

Table 2 compares the observed distribution of deaths with that expected, by year of death and type of anaemia. Of the 227 deaths coded to anaemia in textile and clothing workers, $74(33 \%)$ were attributed to pernicious anaemia, $57(25 \%)$ to aplastic anaemia, $19(8 \%)$ to iron deficiency anaemia, and $77(34 \%)$ to other and unspecified anaemias. The relative frequency of each type of anaemia is not the same as in England and Wales $\left(\chi^{2}=10.9, \mathrm{df}=3\right.$, $\mathrm{p}<0.05)$. The most notable difference occurs for pernicious anaemia (74 observed $v 55$ expected deaths, $p<0.05$ ). This excess mortality from pernicious anaemia is evident for each of the three time periods, but is most obvious for the five years 1959-63.

Table 1 Sex, age, and region of residence of death of textile and clothing workers who died aged 15-74 with anaemia coded as the underlying cause of death. England and Wales by year of death

\begin{tabular}{|c|c|c|c|c|}
\hline & \multicolumn{4}{|c|}{ Year of death } \\
\hline & $\begin{array}{l}1959-63 \\
(n=99)\end{array}$ & $\begin{array}{l}1970-75^{\star} \\
(n=93)\end{array}$ & $\begin{array}{l}1979-83 \dagger \\
(n=35)\end{array}$ & $\begin{array}{l}\text { All years } \\
(n=227)\end{array}$ \\
\hline \multicolumn{5}{|l|}{$\operatorname{Sex}(\%)$} \\
\hline Women & $52 \cdot 5$ & 55.9 & $71 \cdot 4$ & $56 \cdot 8$ \\
\hline \multicolumn{5}{|l|}{ Age $(\%):$} \\
\hline$<54$ & $9 \cdot 1$ & $9 \cdot 7$ & $8 \cdot 6$ & $9 \cdot 3$ \\
\hline-64 & $18 \cdot 2$ & $10 \cdot 8$ & $22 \cdot 9$ & $15 \cdot 9$ \\
\hline \multirow{2}{*}{\multicolumn{5}{|c|}{ Region of residence $(\%)$ : }} \\
\hline $\begin{array}{l}\text { Region or residence }(\%) \\
\text { Greater Manchester }\end{array}$ & & & & \\
\hline West Yorkshire & $\begin{array}{l}20 \cdot 1 \\
19 \cdot 8\end{array}$ & $23 \cdot 7$ & $25 \cdot 7$ & $22 \cdot 7$ \\
\hline Lancashire & $15 \cdot 8$ & $\begin{array}{l}17 \cdot 2 \\
14 \cdot 0\end{array}$ & $\begin{array}{l}22 \cdot 8 \\
17 \cdot 1\end{array}$ & $\begin{array}{l}19 \cdot 2 \\
15 \cdot 3\end{array}$ \\
\hline Greater London & 5.9 & 8.6 & $17 \cdot 1$ & $8 \cdot 7$ \\
\hline Elsewhere & $38 \cdot 4$ & $36 \cdot 5$ & $17 \cdot 1$ & $34 \cdot 1$ \\
\hline
\end{tabular}


Table 2 Numbers of deaths observed (Obs) and expected $\dagger$ (Exp) by type of anaemia in textile and clothing workers aged 1574. England and Wales by year of death

\begin{tabular}{|c|c|c|c|c|c|}
\hline Type of anaemia & $\begin{array}{l}1959-63 \\
\text { Obs Exp }\end{array}$ & $\begin{array}{l}1970-75 \ddagger \\
\text { Obs Exp }\end{array}$ & $\begin{array}{l}1979-83 \S \\
\text { Obs Exp }\end{array}$ & $\begin{array}{l}\text { All y } \\
\text { Obs }\end{array}$ & $\stackrel{\operatorname{ars}}{\operatorname{Exp}}$ \\
\hline $\begin{array}{l}\text { Pernicious } \\
\text { Aplastic } \\
\text { Iron deficiency } \\
\text { Other and unspecified }\end{array}$ & $\begin{array}{rr}45 & 31 \cdot 6 \\
20 & 30 \cdot 5 \\
8 & 14 \cdot 8 \\
26 & 22 \cdot 1\end{array}$ & $\begin{array}{r}19 \cdot 5 \\
26 \cdot 8 \\
8 \cdot 5 \\
38 \cdot 2\end{array}$ & $\begin{array}{rr}7 & 3.9 \\
11 & 11 \cdot 7 \\
4 & 3.4 \\
9 & 16.0\end{array}$ & $\begin{array}{l}74 \\
57 \\
19 \\
77\end{array}$ & $\begin{array}{l}55 \cdot 0^{\star} \\
69 \cdot 0 \\
26 \cdot 7 \\
76 \cdot 3\end{array}$ \\
\hline Total & $99 \cdot 0$ & 93.0 & $35 \cdot 0$ & 227 & $227 \cdot 0$ \\
\hline
\end{tabular}

$\star$ Obs differs from exp (p<0.05).

†Adjusted for age, sex, and year of death.

$\ddagger$ Excluding 1974.

§Excluding 1981 .

The occupational distribution of textile and clothing workers whose death was attributed to anaemia is similar to that of randomly selected textile and clothing workers whose death was attributed to other causes (table 3 ). In both groups, nearly half of the deaths were to textile mill workers, and about a third were to textile goods production and clothing workers. The occupational distribution of those whose death was attributed to pernicious anaemia was different, however, with around two thirds being textile mill workers (table 4). Those who died from pernicious anaemia were more than twice as likely as their randomly selected matched controls to have worked in a textile mill (odds ratio $=2.4,95 \%$ confidence interval ( $95 \% \mathrm{CI}) 1 \cdot 4-4 \cdot 2)$, and correspondingly less likely to have been engaged in other textile work or with the making of textile goods.

The analyses shown in tables 3 and 4 were repeated separately for men and for women by region of death and place of birth for the three different time periods. The same association between pernicious anaemia and textile mill work was found, although the numbers were small. The analysis was also repeated including only those textile mill workers in which industry was specifically stated on the death certificate. The result was the same.

Of the 74 deaths attributed to pernicious anaemia, $56(76 \%)$ had one or more associated causes of death listed on the death certificate. The most common associated cause mentioned was heart failure $(41 \%)$ and bronchopneumonia $(11 \%)$. Table 5 summarises certain information recorded on the death certificates of the seven textile and clothing workers whose death was attributed to pernicious anaemia in the years around the 1981 census. For five cases heart failure was recorded as an associated cause of death and for two no other conditions were noted. All but two of the deaths occurred in hospital, and in four cases a post mortem examination was performed.

Further evidence that risk of pernicious anaemia may be increased in textile mill workers comes from the 1931 Registrar General's decennial supplement on occupational mortality. ${ }^{1}$ In this report the standardised mortality ratios (SMRs) for pernicious anaemia were presented separately from other diseases of the blood for men in certain occupational groups (table 6). For each of the five textile mill occupational groups (groups 29-33) mortality from pernicious anaemia was higher than in England and Wales as a whole. The pooled SMR for pernicious anaemia was 200 ( $p<0.01$, based on 28 deaths). By contrast, the overall level of mortality of these five groups was, on average, the same as that of England and Wales (SMR $=100$, based on 2651 deaths). Only data on dyers (group 34) and makers of textile goods (group 35) were presented for other textile and clothing workers. No data for women or for other anaemias were given in the 1931 report; and no other national report on occupational mortality has included separate data on mortality attributed to pernicious anaemia.

\section{Discussion}

Our study was designed to investigate the excess mortality from anaemia and associated disorders in textile and clothing workers and to assess whether it

Table 3 Occupational distribution (\%) of textile and clothing workers. England and Wales by cause of death

\begin{tabular}{lcc}
\hline & \multicolumn{2}{c}{ Underlying cause of death } \\
\cline { 2 - 3 } & $\begin{array}{l}\text { All } \\
\text { anaemias } \\
(n=227)\end{array}$ & $\begin{array}{l}\text { All causes } \\
\text { except anaemia } \\
(n=678)\end{array}$ \\
\hline Textile mill workers & 46.7 & 44.5 \\
Cotton & 30.8 & $30 \cdot 2$ \\
Wool & 12.8 & 13.4 \\
Silk & 3.1 & 0.9 \\
Other textile workers & 15.9 & 16.5 \\
Dye and bleach & 1.8 & 3.7 \\
Textile goods production & & \\
and clothing & $35 \cdot 2$ & 33.2 \\
Machinists & 20.8 & 27.7 \\
Not classified elsewhere & 2.2 & 5.5 \\
\hline
\end{tabular}


Table 4 Occupational distribution (\%) of textile and clothing workers who died from pernicious anaemia and their matched controls who died from other causes. England and Wales

\begin{tabular}{|c|c|c|c|}
\hline & \multicolumn{3}{|c|}{ Underlying cause of death } \\
\hline & $\begin{array}{l}\text { Pernicious anaemia } \\
(n=74)\end{array}$ & $\begin{array}{l}\text { All causes except anaemia } \\
(n=219)\end{array}$ & Odds ratio $(95 \% \mathrm{CI})$ \\
\hline $\begin{array}{l}\text { Textile mill workers } \\
\text { Cotton } \\
\text { Wool } \\
\text { Silk }\end{array}$ & $\begin{array}{r}66 \cdot 2 \\
43 \cdot 2 \\
17 \cdot 6 \\
5 \cdot 4\end{array}$ & $\begin{array}{r}44 \cdot 3 \\
32 \cdot 0 \\
10 \cdot 5 \\
1 \cdot 8\end{array}$ & $\begin{array}{l}2 \cdot 4(1 \cdot 4-4 \cdot 2)^{\star} \\
1 \cdot 6(0 \cdot 9-2 \cdot 6) \\
2 \cdot 1(0 \cdot 9-4 \cdot 8) \\
3 \cdot 0(0 \cdot 8-12 \cdot 0)\end{array}$ \\
\hline $\begin{array}{l}\text { Other textile workers } \\
\text { Dye and bleach }\end{array}$ & $\begin{array}{l}6 \cdot 8 \\
1 \cdot 4\end{array}$ & $\begin{array}{r}16 \cdot 9 \\
5 \cdot 5\end{array}$ & $\begin{array}{l}0 \cdot 4(0 \cdot 1-1 \cdot 0)^{\star} \\
0 \cdot 2(0 \cdot 0-1 \cdot 9)\end{array}$ \\
\hline $\begin{array}{l}\text { Textile goods production and clothing } \\
\text { Machinists }\end{array}$ & $\begin{array}{l}24 \cdot 3 \\
21 \cdot 6\end{array}$ & $\begin{array}{l}33 \cdot 4 \\
28 \cdot 8\end{array}$ & $\begin{array}{l}0.6(0.4-1 \cdot 2) \\
0.7(0.4-1 \cdot 3)\end{array}$ \\
\hline Not classified elsewhere & $2 \cdot 7$ & $5 \cdot 5$ & $0.5(0 \cdot 1-2 \cdot 4)$ \\
\hline
\end{tabular}

was associated with any particular types of anaemia or specific jobs. The findings suggest that the increased mortality from anaemia may be due to an increased risk of pernicious anaemia in textile mill workers.

The distribution of the different types of anaemia in the textile and clothing industry as a whole was found to be unusual with comparatively more deaths from pernicious anaemia than normally occur (table 2). It is, however, neither possible to estimate the magnitude of the increased risk of pernicious anaemia, nor the level of any other type of anaemia in textile and clothing workers compared with the general population as the data in table 2 are of relative rather than absolute frequencies. Nor is it possible to estimate the magnitude of the increased risk of pernicious anaemia in textile mill workers alone, as the case-control investigation was confined to workers in the textile and clothing industry (table 4). Thus although it can be concluded that textile mill workers are more likely to die from pernicious anaemia than are other textile and clothing workers, absolute levels of risk cannot be calculated and comparisons with the general population cannot be made. These analyses are, however, likely to underestimate the risks associated with specific anaemias and occupational groups, as mortality from all anaemias is already known to be high in textile and clothing workers. ${ }^{1-5}$ The only existing data that permit some estimate of the absolute increase in risk come from the 1931 decennial supplement, in which the SMR from pernicious anaemia was twice as high in textile mill workers as in the general population (table 6).

Since the purification of Vitamin $B^{12}$ in 1948 and the introduction of $B^{12}$ replacement therapy, pernicious anaemia has become a treatable disease and is rarely fatal. ${ }^{12}$ A few deaths are, however, still attributed to pernicious anaemia and in England and Wales there were 152 such deaths recorded in $1988 .{ }^{13}$ Review of the death certificates of those studied here did not suggest that pernicious anaemia as a cause of death was likely to have been recorded in error (table 5).

The aetiology of pernicious anaemia is not well understood. ${ }^{12}$ Our findings suggest that occupational factors, specifically work in textile mills, could be involved. The inhalation of dust from cotton and flax has long been known to cause byssinosis. ${ }^{14}$ Ingestion of textile dust and fibres might also effect the gastric mucosa and normal action of intrinsic factor. Per-

Table 5 Death certificate details for the seven textile and clothing workers whose death was attributed to pernicious anaemia in England and Wales in the years around the 1981 census

\begin{tabular}{lllllll}
\hline Age & Sex & $\begin{array}{l}\text { Year of } \\
\text { death }\end{array}$ & $\begin{array}{l}\text { Place of } \\
\text { death }\end{array}$ & Postmortem & Underlying cause of death & Associated cause of death \\
\hline 40 & M & 1979 & Hospital & No & Severe pernicious anaemia & Cardiac failure \\
43 & W & 1979 & Hospital & Yes & Pernicious anaemia & Congestive cardiac failure \\
61 & W & 1980 & Home & Yes & Pernicious anaemia & Congestive cardiac failure \\
66 & W & 1979 & Hospital & Yes & Severe pernicious anaemia & - \\
67 & M & 1979 & Hospital & Yes & Pernicious anaemia & $\begin{array}{l}\text { Myocardial failure } \\
72\end{array}$ \\
72 & W & 1980 & Home & No & Pernicious anaemia & Congestive cardiac failure \\
\hline
\end{tabular}

$\mathrm{M}=\mathrm{Man}, \mathrm{W}=$ woman. 
Table 6 Standardised mortality ratios (SMRs) and observed deaths (Obs) from pernicious anaemia in male textile and clothing workers dying in England and Wales 1930-32

\begin{tabular}{llc}
\hline & Underlying cause of death & \\
\cline { 2 - 3 } Occupational group & Pernicious anaemia (SMR (Obs)) & All causes (SMR (Obs)) \\
\hline Textile mill workers: & $175(7)$ & $105(935)$ \\
29 Spinners (cotton) & $300(3)$ & $90(151)$ \\
30 Spinners (wool) & $171(12)$ & $94(1141)^{\star}$ \\
31 Weavers (cotton) & $400(4)^{\star}$ & $100(237)$ \\
32 Weavers (wool) & $200(2)$ & $145(187)^{\star}$ \\
33 Strippers and grinders (cotton) & $200(28)^{\star \star}$ & $100(2651)$ \\
$29-33$ Total & $167(5)$ & $123(640)^{\star}$ \\
Other textile workers: & & $93(2011)^{\star}$ \\
34 Dyers & $83(10)$ & \\
Textile goods production and clothing & &
\end{tabular}

$\star 0.01<\mathrm{p}<0.05$.

$\star \star \mathrm{p}<0.01$.

+Source: Registrar General's decennial supplement 1931.'

nicious anaemia and stomach cancer are both related to gastric atrophy and achlorhydria, ${ }^{12}$ and mortality from stomach cancer has often been reported to be increased in male and female textile workers. ${ }^{1-3515}$ It is possible that the same occupational exposure could be a factor in both diseases. Other mechanisms are also possible, and although the associations described here were not explained by age, sex, place of residence at death, or place of birth, we cannot exclude the possibility that other, as yet unknown, factors could be responsible. A need exists for further study of the pathogenesis of pernicious anaemia in textile mill workers.

1 Office of Population Censuses and Surveys. Occupational mortality: the Registrar General's decennial supplement part IIa 1931. London: HMSO, 1936.

2 Office of Population Censuses and Surveys. Occupational mortality: the Registrar General's decennial supplement 1970-72, Series DS1. London: HMSO, 1978.

3 Kirby P. Death in the textile industry. Bradford: The Transport and General Workers Union (textile Group). The Club Press.

4 Roman E, Beral V, Inskip H. Occupational mortality among women in England and Wales. BMJ 1985;291:194-6.

5 Dubrow R, Gute D. Cause-specific mortality among male textile workers in Rhode Island. Am J Ind Med 1988;13:439-54.

6 World Health Organisation. International classification of diseases; $7 \mathrm{th}, 8 \mathrm{th}$, and $9 \mathrm{th}$ revision conferences. Geneva: WHO, $1957 ; 1969 ; 1978$.

7 Office of Population Censuses and Surveys. Local government in England and Wales: a guide to the new system. London: HMSO, 1974.

$8 d B A S E$ 111. California 90502-1319 USA: Ashton-Tate Corporation.

9 Office of Population Censuses and Surveys. Registrar General's Review of England and Wales. London: HMSO, 1959-63 and 1970-4.

10 Office of Population Censuses and Surveys. Mortality Statistics, Series DH2 Nos 2, 6-7, 9-10. London: HMSO, 1975-83.

11 Statistics and Epidemiology Research Corporation (SERC) EGRET. Software Division 909, NE 43rd Street, 310 Seattle, Washington 98105: SERC.

12 Chanarin I. The megaloblastic anaemias: second edition. Oxford: Blackwell Scientific, 1979.

13 Office of Population Censuses and Surveys. Mortality Statistics Series DH2 No 15. London: HMSO, 1990

14 Beck G, Schachler M, Lucinda R, Maunde M, Schilling R. A prospective study of chronic lung disease in cotton textile workers. Ann Intern Med 1982;97:645-51.

15 International Agency for Research on Cancer. Monographs on the evaluation of carcinogenic risks to humans: some flame retardants and textile chemicals, and exposures in the textile manufacturing industry. Vol 48. Lyon: IARC, 1990.

Accepted 26 November 1990 